\title{
Diversity and specialization of mammalian SWI/SNF complexes
}

\author{
Weidong Wang, ${ }^{1}$ Yutong Xue, ${ }^{1}$ Sharleen Zhou, ${ }^{2}$ Ann Kuo, ${ }^{1}$ Bradley R. Cairns, ${ }^{3}$ and \\ Gerald R. Crabtree ${ }^{1,4}$ \\ ${ }^{1}$ Howard Hughes Medical Institute, Department of Developmental Biology, Stanford University, Stanford, California \\ 94305-5428 USA; ${ }^{2}$ Department of Molecular and Cell Biology, Howard Hughes Medical Institute, University of California, \\ Berkeley, California 94720-3204 USA; ${ }^{3}$ Department of Cell Biology, Stanford University, Stanford, California 94305 USA
}

The SWI/SNF complex in yeast facilitates the function of transcriptional activators by opposing chromatin-dependent repression of transcription. We demonstrate that in mammals SWI/SNF complexes are present in multiple forms made up of 9-12 proteins that we refer to as BRG1-associated factors (BAFs) ranging from 47 to $250 \mathrm{kD}$. We have isolated cDNAs for human BAF155, BAF170, and BAF60. BAF155 and BAF170 are encoded by separate genes that are both homologs of yeast SWI3. Both contain a region of similarity to the DNA binding domain of myb, but lack the basic residues known to be necessary for interaction with DNA. The two SWI3 homologs copurify on antibody columns specific for either BAF155 or BAF170, indicating that they are in the same complex. BAF60 is encoded by a novel gene family. An open reading frame from yeast, which is highly homologous, encodes the previously uncharacterized 73-kD subunit of the yeast SWI/SNF complex required for transcriptional activation by the glucocorticoid receptor (Cairns et al., this issue). BAF60a is expressed in all tissues examined, whereas BAF60b and BAF60c are expressed preferentially in muscle and pancreas, respectively. BAF60a is present within the 2000-kD BRG1 complex, whereas BAF60b is in a distinct complex that shares some but not all subunits with the BRG1 complex. The observed similarity between mammalian BAF190, BAF170, BAF155, BAF60, and BAF47 and yeast SNF2/SWI2, SWI3, SWI3, SWP73, and SNF5, respectively, underscores the similarity of the mammalian and yeast complexes. However, the complexes in mammals are more diverse than the SWI/SNF complex in yeast and are likely dedicated to developmentally distinct functions.

[Key Words: SWI; SNF; BRG1; BAF; SWP; chromatin]

Received May 23, 1996; revised version accepted July 22, 1996.

Chromatin is actively remodeled during development, as indicated by the observations that the same genetic locus in different tissues varies dramatically in its sensitivity to DNAse I (Weintraub and Groudine 1976; Wu and Gilbert 1981) and restriction enzymes (McGhee et al. 1981). During development of specific cell types, chromatin remodeling of certain genes appears to precede the transcriptional activation of the gene (Siebenlist et al. 1986), suggesting that chromatin remodeling may occur in anticipation of developmental transitions. The mechanisms underlying these developmental changes in chromatin structure are unclear. In Saccharomyces cerevisiae, the products of five genes, SWI1 (ADR6), SWI2(SNF2), SWI3, SNF5, and SNF6, are thought to function by remodeling chromatin to aid transcription factors required for specific inducible genes such as $\mathrm{HO}$ and SUC2 (Neigeborn and Carlson 1984; Stern et al. 1984; Breeden and Nasmyth 1987; for review, see Winston and Carlson 1992; Carlson and Laurent 1994; Peterson and Tamkun

${ }^{4}$ Corresponding author.
1995|. Recent evidence from both genetic and biochemical studies indicates that these five proteins function together as onc multisubunit complex. For example, single and double SWI/SNF mutants were shown to have similar phenotypes (Peterson and Herskowitz 1992). Each of the five SWI/SNF gene products is involved in regulation of the same set of genes (for review, see Peterson and Herskowitz 1992; Winston and Carlson 1992). Immunoprecipitation using antibodies against different SWI/SNF proteins purified all five proteins, indicating they are subunits of one complex. Six additional polypeptides have been found in the complex and two of them were identified as TFG3 and SNF11 (Cairns et al. 1994; Peterson et al. 1994; Treich et al. 1995; Cairns et al. 1996a).

The SWI/SNF complex appears to remodel chromatin structures by an unknown mechanism (for review, see Winston and Carlson 1992; Carlson and Laurent 1994; Wolffe 1993; Peterson and Tamkun 1995|. Several genetic suppressors of swi/snf mutants have been identified as components of chromatin, such as H2A, H2B, H3, H4 (Hirschhorn et al. 1992, 1995; Prelich and Winston 1993; Kruger et al. 1995). The chromatin structure at the 
SUC2 promoter is altered in swi/snf mutants, a change that is independent of transcription (Hirschhorn et al. 1992). Moreover, the purified yeast SWI/SNF complex has an ATP-dependent activity that enables it to disrupt mononucleosomes and facilitate binding of GAL4 derivatives to the nucleosome core in vitro (Côté et al. 1994). Thus, one model for the function of the SWI/SNF complex is that it facilitates the ability of transcriptional activators to overcome the repressive effects of chromatin (Travers 1992).

Several lines of evidence suggest that higher eukaryotes contain homologs of the yeast SWI/SNF complex. First, transcriptional activation by the rat glucocorticoid receptor (GR), the Drosophila bicoid factor, and $f t z$ were shown to be dependent on SWI/SNF function when ectopically expressed in yeast (Laurent and Carlson 1992; Peterson and Herskowitz 1992; Yoshinaga et al. 1992). In addition, two Drosophila homologs of the SWI/SNF proteins, brm (a homolog of SWI2) and inr1 (a homolog of SNF51, have been identified and are present in a highmolecular-weight complex similar in size to the yeast complex (Tamkun et al. 1992, Dingwall et al. 1995). brm was originally identified as a suppressor of mutations in polycomb (Kennison and Tamkun 1988), a repressor of several homeotic genes that is thought to act by regionally compacting chromatin (for review, see Moehrle and Paro 1994). Thus, brm itself may be involved in modification of chromatin structure. brm and INRI are required for proper expression of several homeotic genes (Tamkun et al. 1992; Brizuela et al. 1994; Dingwall et al. 1995). Flies lacking either one die at embryonic stages.

In humans, the two closest relatives of SWI2, BRG1 and hbrm, have been implicated to be functional homologs of SWI2 (Khavari et al. 1993; Muchardt and Yaniv 1993; Chiba et al. 1994). Another protein, INI1/ hSNF5, has been reported to be an SNF5 homolog (Kalpana et al. 1994; Muchardt et al. 1995). BRG1 is present in a high-molecular-mass complex of $2 \mathrm{MD}$, similar in size to the yeast complex (Khavari et al. 1993). Kwon et al. (1994) have reported partial purification of two BRG1containing complexes from HeLa nuclear extracts by following BRG1 immunoblot reactivity. They showed that their partially purified fractions contain an activity similar to the yeast SWI/SNF complex that can disrupt nucleosomes and facilitate the binding of GAL4 derivatives and TBP to a nucleosome core (Kwon et al. 1994; Imbalzano et al. 1994). We have recently reported complete purification of distinct complexes containing either BRG1 or hbrm using a combination of conventional chromatography and immunoaffinity methods /Wang et al. 1996). The purified BRG1 or hbrm complexes contain 9-12 polypeptides (depending on the cell lines used for the purification). They were referred to as BAFs (BRG1 associated factors|. These polypeptides are different from the partially purified fractions reported by Kwon et al. (1994). The discrepancy most likely relates to the fact that the affinity columns allow a single-step purification of 500- to 1000-fold. By microsequencing, immunoblotting, and immunoprecipitation, we showed that the BAF47 subunit is INI1/hSNF5, a mammalian homolog of SNF5. Like the yeast SWI/SNF complex, the complexes we purified possess an ATP-dependent nucleosome disruption activity and are able to facilitate binding of GAL4-VP16 to mononucleosomes. These data strongly suggest that BRGl- and hbrm-containing complexes are mammalian homologs of the yeast SWI/SNF complex. Purification of SWI/SNF complexes from different mammalian cell lines revealed the presence of multiple forms of SWI/SNF complexes within the same cell or in different cell lines.

As a first step toward understanding the role of the SWI/SNF complex in the developmental remodeling of chromatin, we report the isolation of genes encoding subunits BAF170, BAF155, and BAF60. Our results underscore the similarity of the yeast and mammalian complexes, because BAF155 and BAF170 are homologs of SWI3. Furthermore, the sequence of BAF60 is highly similar to an open reading frame in Saccharomyces cerevisiae, that encodes the $73-\mathrm{kD}$ component of the yeast SWI/SNF complex (SWP73) (Cairns et al., this issue), strongly indicating that BAF 60 is a functional component of the mammalian complex. BAF60 is encoded by a multigene family that is expressed selectively and participates in distinct SWI/SNF-like complexes. These results imply that although the SWI/SNF complex is likely to have a universal function common to all eukaryotes, this function has been adapted to specialized cellular and developmental needs in multicellular eukaryotes.

\section{Results}

\section{Purification of mammalian SWI/SNF complexes}

We have purified the SWI/SNF complexes from the human YT cell line using a combination of conventional chromatography and immunoaffinity purification with the BRGl antibody (Fig. 1; Wang et al. 1996). Two forms of BRGl complexes, as judged by their different subunit composition, have been purified from this cell line. Complex A, which is the more abundant form in the cell, contains nine subunits with apparent molecular masses of $250,190,170,150,110,60,57,53$, and $47 \mathrm{kD}$ (Fig. 1b, lane 1). The BAF47 subunit of the complex has been identified as INI1/hSNF5 by microsequencing, immunoblotting, and immunopurification (Wang et al. 1996). Purification with an antibody against INI1/hSNF5 yields an almost identical pattern as with the BRGl antibody (Fig. 1b, lane 2). The data strongly indicate that these nine polypeptides are components of one complex.

Microsequencing and cloning of BAF155 and BAF170 reveals that they belong to the same gene family as yeast SWI3

To define additional subunits of the BRG1 complexes we separated individual subunits of purified complex A by preparative gel electrophoresis and determined the sequence of peptides from BAF155, BAF170, and BAF60 (see Materials and Methods). Four peptide sequences were obtained for human BAF155 after Lys-C endopro- 
(a)

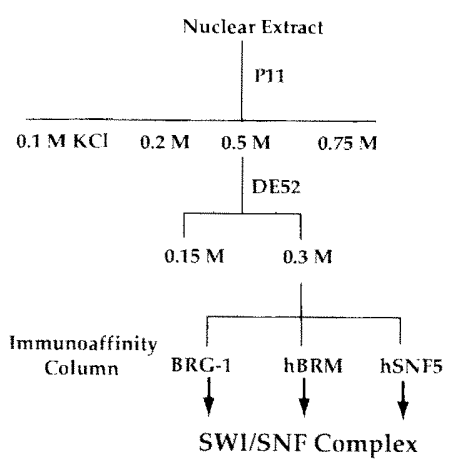

(b)

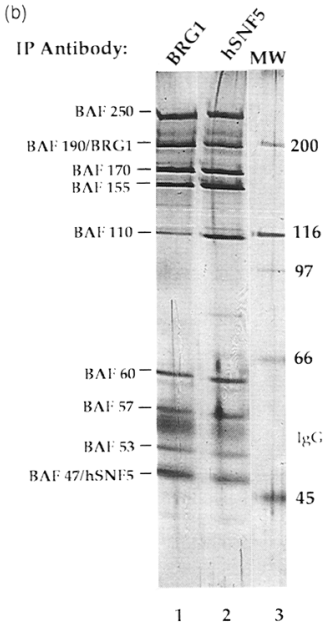

Figure 1. Purification of mammalian SWI/SNF complex. $(a)$ Purification scheme for mammalian SWI/SNF complex A. Two different forms of mammalian SWI/SNF complexes (A and B) were present in most cell lines and tissues and both BRGl and hbrm complexes exist in two forms (Wang et al. 1996). The purification scheme is for complex A from cultured cells. Purification using animal tissues requires an extra S300 column. $(b)$ The silver stain gel of the purified human SWI/SNF complex A. The antibodies against BRG1 or hSNF5/INII/BAF47 were used in immunoaffinity purification and were indicated on top of each lane. The eluted polypeptides were named as BAFxx (see text; $x x$ refers the apparent molecular weight). The band between BAF53 and BAF57 is the immunoglobulin heavy chain.

teinase digestion (Fig. 2). cDNA clones were isolated from a human Jurkat $\mathrm{T}$ cell cDNA library (see Materials and Methods|. Sequencing and mapping of selected clones revealed a single long open reading frame of 1104 amino acids. All peptide sequences obtained from microsequencing were found in this open reading frame. Immunoprecipitation and immunoblotting using an antibody against a region of the clone confirms that it is indeed the gene encoding human BAF155/see Fig. 8 and below)

Three high-quality peptide sequences were obtained for human BAF170 after Lys-C endoproteinase digestion (Fig. 2a; see Materials and Methods). Degenerate oligos were designed based on the longest peptide sequence (amino acids 733-752 of the cloned BAF170; Fig. 2a) and were used to isolate cDNA clones from a Jurkat T-cell cDNA library under low-stringency washing conditions. Sequencing of the clones obtained revealed a single open reading frame of 1213 amino acids containing all three peptide sequences from microsequencing. Immunoprecipitation and immunoblotting with an antibody against part of the sequence showed that it is indeed the gene encoding human BAF170 (see Fig. 8 and below).

Interestingly, BAF170 and BAF155 are highly similar to each other; they are $62 \%$ identical and $77 \%$ similar at the amino acid level (Fig. 3a). A search of the NR databank at the NCBI with BAF170 and BAF155 protein sequences using the BLAST program revealed two signifi-

cant matches, yeast SWI3 protein (retrospective probability $10^{-73}$ ) and a second open reading frame from Saccharomyces cerevisiae identified by the genome sequencing project, YFK7 (SwissProtein bank Accession no. P43609, retrospective probability $10^{-66} \%$. Sequence comparison between SWI3 and YFK7 showed that they are also similar to each other. Overall, they are $30 \%$ identical and $52 \%$ similar. We will refer to YFK7 as SWI3b (Fig. 3). The similarity between the two yeast SWI3 genes is much lower than the similarity between the two human genes (Table 1).

The conserved regions of the SWI3 gene family include a myb-like tryptophan repeat and a coiled-coil region

The alignment of the two human and the two yeast genes revealed three conserved regions in all four proteins (Fig. 3a,b). Region I is the longest and has the greatest similarity of all three regions. Most of the conserved residues are prolines, hydrophobic, and aromatic amino acids, suggesting that this domain is hidden inside of the complex.

Region II of these proteins is a tryptophan-repeat domain, identificd originally in the myb family of proteins (Fig. 3c). This domain is present in two or three tandem repeats in the myb family of proteins from all species and is involved in sequence-specific DNA binding (for review, see Luscher and Eisenman 1990|. Recently, this domain was termed SANT domain and was thought to bind DNA as it does in the myb family of proteins (Aasland 1996). However, a bacterial fusion protein containing all three conserved regions of BAF170 has no detectable DNA-binding activity, as determined by gelshift assays (data not shown).

The conserved region III of the SWI3 gene family contains a predicted leucine-zipper region first recognized in the yeast SWI3 gene (Peterson and Herskowitz 1992). The leucine-zipper or coiled-coil was identified as a dimerization domain for a variety of DNA-binding transcription factors, such as C/EBP, Fos-Jun-GCN4, ATF and Myc-Mad-Max families of proteins (for review, see Johnson and McKnight 1989). Because the mammalian BRG1 complex contains both BAF155 and BAF170 (see below), it is possible that this coiled-coil region serves as the dimerization domain for the complex.

Table 1. The homology between the human and yeast SWI3 gene homologs

\begin{tabular}{llll}
\hline Identity/similarity & BAF155 & BAF170 & ySWI3 \\
\hline BAF155 & & & \\
BAF177 & $62 / 77 \%$ & & \\
ySWI3 & $30 / 50 \%$ & $30 / 49 \%$ & \\
ySWI3b & $29 / 51 \%$ & $31 / 51 \%$ & $30 / 52 \%$
\end{tabular}

Each of the two human SWI3 homologs (BAF155 and BAF170) or yeast proteins (SWI3 and SWI3b) were aligned against each other by using the Bestfit program of UWGCG. The calculated percentage of identical or similar amino acids is shown. SWI3b refers to a ycast open reading frame, YFK7 (see text). 
Wang et al.

BAF155

$$
1 \ldots
$$

MAAAMGgGgPGTAVGATGFgDSAAAAg 27

BAF 170

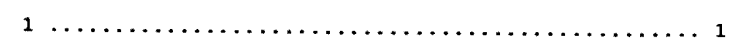

28 LAVYRRKDGGPATKFWESPETV SQLDSVRVWLGKHYKKYVHADAPTNRTL 77

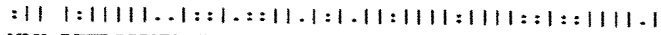
1 MAV. RKRDGGPNVKYYEAXDTVTOFDWVRLLGKNYKXYIOAEP PTNKSL 49

78 AGLVVQLLQFOEDAFGKHVTNPAFTKLPAKCFIDFKAGGALCHILGAAYK 127 $:=11\|1\| 11 \|:=11111.1:=: 11 \mid 111: 111111.11111: 1111$ 50 SSLVVOLLOFOEEVFGKHVSNAPLTKLPIKCFLDFRAGGSLCHILAAAYK 99

128 YKNEQGWRRFDLQNPSRMDRNVEMFANIEKTLVQNACLTRPNIYLIPDID 177 $: 1 .: 11111: 1=11111111111111.111 .1111111 .1111: 1.1: 1$ : 100 FKSDQGWRRYDPONPSRUDRNVEYRTIIRKSLVQNACLSRPNIPLCPEIE 149

178 LKLANKLKDI IKRHQGTPTDEKSKASHHI YPYSS SODDEEWLRPVMRREK 227 $11.11111+111111.1:: 1 \ldots \mid 11: 11 .:=:: 111: 1111::: 1$ 150 PRLLGKLKDI IKRHQGTVTEDKWDASHVVYPVPGMLEEREWVRPVAKRDK 199

228 QVLVHWGPYPDSYDTWVHSNDVDAEIRDPPIPEKPWKVHVKMILDTDIFN 277

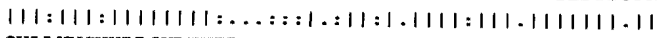
200 QVLLHWGYYPDSYDTWIPASEIEA SVRDAPTPEKPRKVHAKWILDTDTFN 249

278 EWMREEDYEVDENRKPVSFRQRISTKN. BEPVRSP. . ERRDRKASAMARK 324 $1111 \| 1111:::=.1111 .: 11.1 . .:=1.11: \mid 11: 1:: 1: 1$ 250 EWMNEEDYEVNDDKNPVSRRKKI SAKTLTDEVNSPDSDRRDKKG. GNYKK 298

325 RKHSPSPPPPTPTE SRKRSGKKGOASLYGKRRSORERDEOEDLTKDMRDP 374

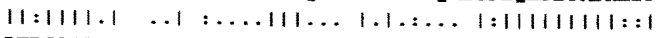
299 RKRSPSPSP. .TPEVKEEKCKKGP STPYTTRSKRGKREREQEDLTXDMDEP 346

375 TPVPNI REVVLPRONNLKKDSEMTPVKGCTVADLDEODEETVTAGGKEDE 424 $.11\|:\| 11.111 .\|1\|\|1 \ldots|1\|11:=11\| \|:=1 .: \ldots| 1::$ : 347 SPVPNVBEVTLP KTVNTKKDSBSA PVKGGTMTDLDEOEDE SIOETTGKDED 396

425 D. . PAKGDQSRSVDLGEDNVTEQTNHT II PSYASWFDYNCIHVIERRAL 471 $\ldots 11: 1.2 .111111111: 1111111.11111:: 1.111111$ 397 BNSTGNKGEQTKOPDLHEDNVTEQTHHI I IPSYAAWPDYNSVHAIBRRAL 446

472 PEFFNGKNRSKT PEI YLA YRNFMIDS YRLNPOEYLT STACRRNLTGDVCA 521 $1111111111111111111111.1111111111 \| 11111.11111$ 447 PEFPNGKNKSKT PEIYLA YRNFAT DTYRLNPOEYLT STACRRNLAGDVCA 496

522 VMRVHAGGEQWGLVNYQVDPESRPMAMGPP PTPHFNVLADTP .. LACASD 569 : $1111|1111:| 1|1|: 1111: 111111.11: 111111$ 1.. 497 ISRVHAFLBQWGLI NYQVDABSRPTPMGPP PT SHFHVLADTP SGLVPLQP 546

570 LRSPQVPAAOQMTN PPEKNKRKPVDLQNFGLRTDIYSKKTLA.KSK.GAS 617 . 1..1.11111111:1.1111.1:11111111:1.11.: : 111:11

547 KTPQQT SASOOMLNFPDKGKEKPTDMONFGLRTDMYTRKNAP SKSKAAAS 596

618 AGRGWTBQETLLLLEALEMYKDDWNKV SEHVGSRTODECILHFLRLPIED 667 $1.1: 1111111111 \| 111111111111111111111111111111$ 597 ATREWTBQETLLLLEALEMYKDDWNKV SEHVGSRTQDEC ILHFLRLPIED 646

668 PYLENSDASLGPLAYQPVPFSQSGNPVMSTVAFLASVVDPRVASAAAKAA 717 \|\|$\|: 1:\|\|\|\|\|\|1\|\|\|\|\|\|\|\|\|\|\|\|\|\|\|\|\|\|\| \| \cdot \mid$ 647 PYLEDSEASLGPLAYOPIPFSOSGNPVMSTVAFLASVVDPRVASAAARSA 696

718 LEGPSRVREEVPLELVEAGVKKVQRAARASGKVDPTYGLESSCIAGTGPD 767

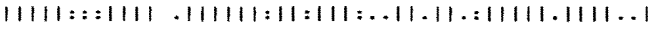
697 LEEFSKOAKEEVPTALVEAHVRKVERAAKVTGKADPAPGLESSGIAGTTSD 746

768 EPRKLE. GAEREKIGADPDGCQPEKAENK. . . VENETDE. . . . 802

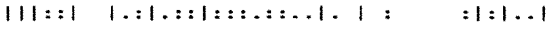

747 EPBRIRE SGNDEARVBGOATDEKKRPKBPREGGGAIRERAREKTSEAPKK 796

803 . GDKAQDGENEKNSEKRQDSEVSEDTKSEBKETEENKELSSTCKERESDT 851

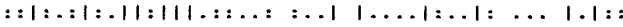

797 DERKGKEGDSBKESEKSDGDPIVDPEK. EKEPKEGOEEVLKEVVVESEGER 845

852 GKKKVRHBI SBGNVATAAAAALASAATKAKHLAAVEERKIKSLVALLVET 901

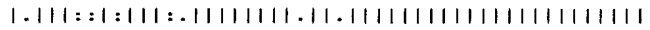
846 . KTKVRRDIGEGNLSTAMAMLAAAAVAKHLAAVEERRIKSIVALLVET 894

902 QKKKLEIRLRHFEGLET IMOREREALEOQROQLLTERONFAREOLKYARL 951

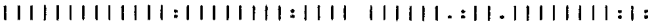
895 OMKKLEIKL RHFEELETTIMTRRREALEYOROOLLADROAFHMROL KYPEM 944

952 RARQQMEQOQHGQNPOOAHQ. HSGGPGLA PLGAAGHPGNA HQQP PPYPL 1000 1111|| $1|1.1 \ldots 1 .: \ldots \ldots 1: \ldots: 1||1| 1.1::$. . : 1: .: 945 RARQQHFQQMHQQQQQP PPALPPGSQPIP PTGAAGPPAVHGLAVAPASVV 994

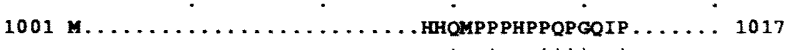
$\therefore 1 \quad 1:=1111,:$ :

995 PAPAGSGAP PGSLGP SEOI COAGSTRGPOOQOPAGAPOPGAVPPGVPPPG 1044

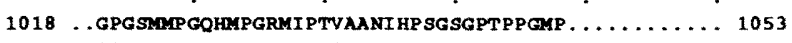

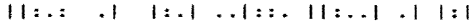

1045 PHGPSPFPNQQTPPSWAPGAVPGSGHPGVAGNAPLGL PFGMPPPPPPPAP 1094

$1054 \ldots \ldots \ldots \ldots \ldots$ PMPGNILG......... PRVPLTAPNGMYP 1074 $1 \mid .1:: 1 \quad 1 .: 1: .: 1 .: .1$

1095 SIIPFGSLADSISINLPAPPNLMGSPPSPVRPGTLPPPNLPVSYGRPLHP 1144

$1075 \ldots$ PPPQOQP PPPPPADGVPPPPAPGPPASAAP $\ldots \ldots \ldots \ldots \ldots \ldots 1104$ 1:. $1 \ldots 1: .1: \ldots: 1 .: 1: 11$.

1145 NLPATTTMPSSLPLGPLGSAAAQSPAIVAAVQGNLPSASPLPDPGTPL 1194

$\ldots \ldots \ldots \ldots \ldots \ldots$

1195 PPDPTAPSPGTVTPVPPQ*

1213

Figure 2. BAF155 and BAF170 are highly similar to each other. The predicted amino acid sequences for human BAF155 (top) and BAF170 (bottom). The underlined sequences indicate the peptide sequences obtained from microsequencing after Lys-C digestion. The proteins used for microsequencing are from human KB cells. The sequences are aligned using the Bestfit program of UWGCG. The sequence of BAF155 was obtained from three overlapping cDNA clones. The total length of DNA is 5188 bp, very close to the size of its mRNA on Northern blot $(\sim 5.5 \mathrm{~kb})$. The sequence of BAF170 was obtained from a contiguous cDNA clone of $4022 \mathrm{bp}$. It is shorter than its mRNA determined by Northern blot $(\sim 5 \mathrm{~kb}$; see Fig. 4 for Northern blots).

In addition to these conserved regions, the amino termini of BAF155 and BAF170 are highly similar to each other but not to the yeast genes (Fig. 3a). Their carboxyl termini are highly proline-rich and somewhat glutamine-rich. Pro-rich and Glu-rich domains are common in a variety of transcription activators (Courey et al. 1989; Mermod et al. 1989).

\section{$B A F 155$ and BAF170 are expressed in a wide range of tissues}

$B A F 155$ and BAF170 mRNA were found in all tissues that have been examined and were expressed at particularly high levels in muscle (Fig. 4). In addition, Western blots of nuclear extracts from cultured cell lines derived from different tissues show that they are expressed in all cell lines examined (data not shown). Finally, the cDNAs of BAF155 and BAF170 match ESTs obtained from melanocytes, testis, breast, spleen, liver, placenta, infant brain, and fetal brain for BAF155, and ESTs obtained from liver and spleen, ovary, breast, placenta, fetal brain, and testis for BAF170 (Fig. 4).

\section{BAF60 is a homolog of SWP73, a novel} SWI/SNF protein

Six peptides obtained from microsequencing of BAF60 from calf thymus matched to an open reading frame [musdl5kzl, protein information resource (PIR) accession no. A30222; Fig. 5] adjacent to the mouse glycerol3-phosphate dehydrogenase gene (Johnston et al. 1989). musd $15 \mathrm{kzl}$ has no known function, but is expressed ubiquitously in mice. To verify that this gene encodes 


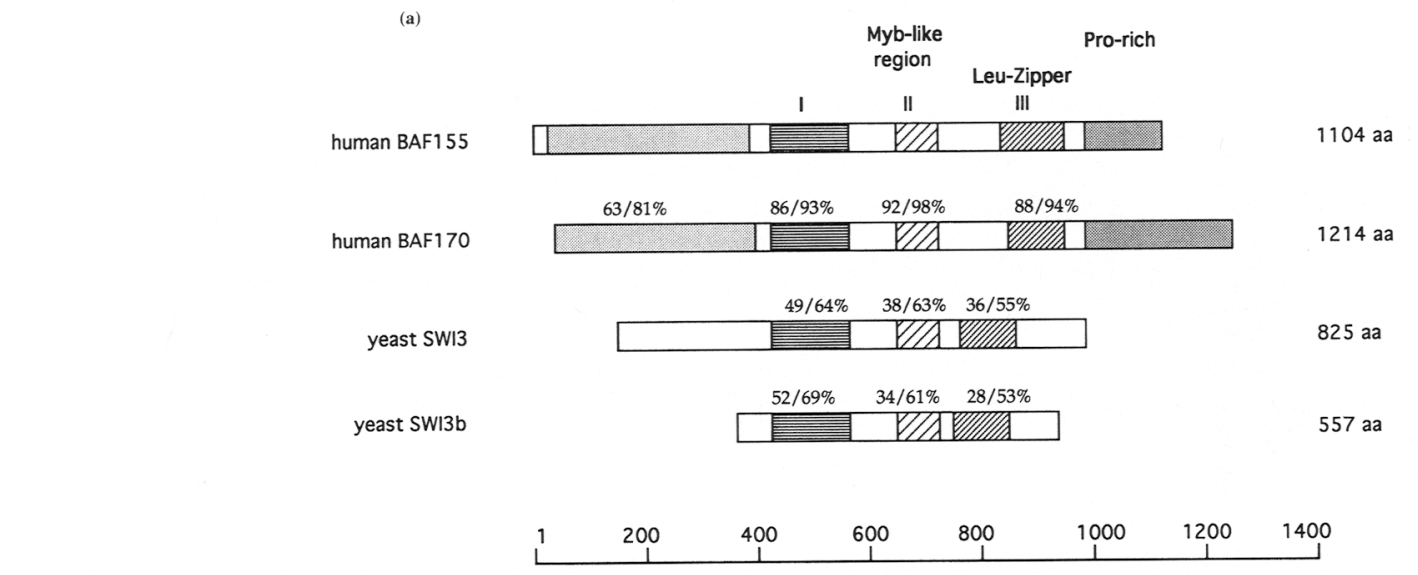

(b)

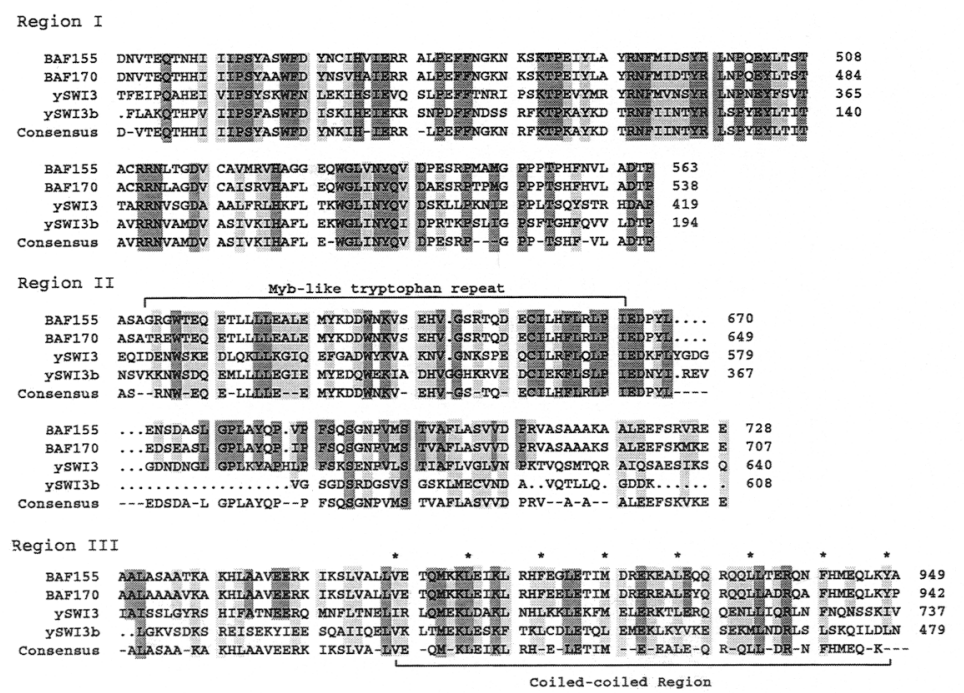

(c)

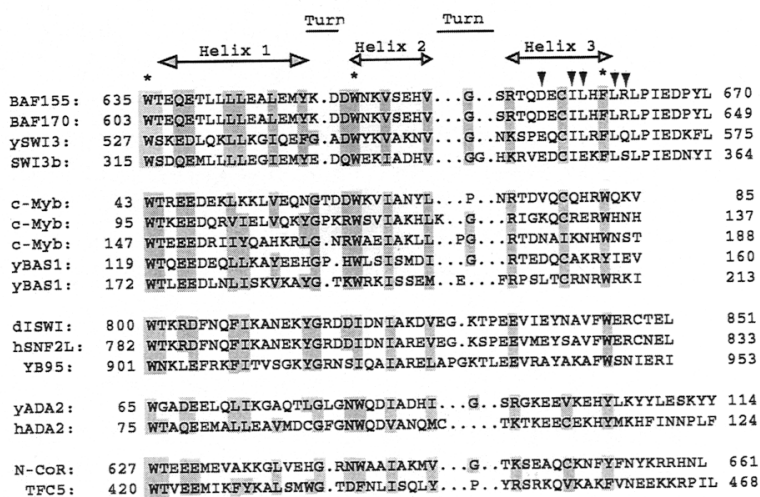

Figure 3. Human BAF155 and BAF170 belong to the yeast $S W I 3$ gene family. (a) The schematic presentation of conserved regions between two human genes, BAF155 and BAF170 and two yeast genes, SWI3 and SWIBb $1 S W I 3 b$ refers to a open reading frame, YFK 7 , SW accession no. p43609). The shaded area indicates the conserved regions. The numbers above each shaded box indicate the percentage of identical and similar amino acid residues of each region using the corresponding region of BAF155 as the standard. They were calculated using the Bcstfit program of UWGCG. $|b|$ The three highly conserved regions among the SWI3 gene family of proteins. The myb-like tryptophan repeat and predicted coiled-coil region are indicated by a bracket. The asterisks mark the hydrophobic residues in the coiled-coil that are separated by seven amino acids. The alignment was performed using the Pileup and Pretty program of UWGCG. (c) The alignment of the myb-like tryptophan repeat of the $S W I 3$ gene family with myb and other transcription factors (see text). We found that the domain is also present as a single repeat in the nuclear receptor corepressor ( $N$-CoR; Horlein et al. 1995) and transcription factor TFC5 (a subunit of TFIIIB; Kassavetis et al. 1995). The helix-turn-helix structure was based on the solution structure of c-myb DNA binding domain (Ogata et al. 1992). The asterisks indicate the conserved tryptophans. The arrows indicate the amino acid residues that presumably interact with DNA if the domain functions similarly as the domain in c-myb. The computer search of the NR data bank at the NCBI was done using the BLAST search program.

BAF60, we made rabbit polyclonal antibodies against two different regions. We find that the human version of d $15 \mathrm{kzl}$ cofractionates with BRGl through several ion exchange columns (data not shown). In particular, they cofractionate as a $2-\mathrm{MD}$ complex on a Superose 6 sizing column (Fig. 6). Immunoblotting of the complexes purified with antibodies against BRG1, hbrm, BAF155, and BAF170 showed that they all contain a homolog of dl5kzl (see Fig. 8, below). Thus, we renamed the musd $15 \mathrm{kzl}$ open reading frame mBAF60a. The published musd $15 \mathrm{kzl}$ sequence has several errors in the carboxyterminal part of the coding region and has no starting methionine. We corrected those errors and defined its starting methionine (Fig. 5; below).

Comparison of the mBAF60a sequence with known yeast SWI/SNF proteins revealed no significant similarities. However, searching the data bank with the BAF60a protein sequence identified three genes with high BLAST 


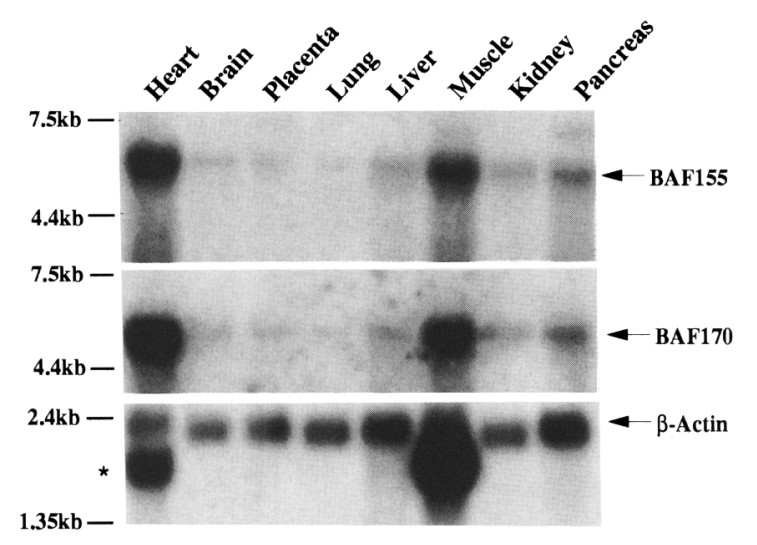

Figure 4. BAF155 and BAF170 are expressed in a wide range of tissues. $(a)$ Northern blot analysis of mRNA from different human tissues as indicated on the top of each lane. The arrows indicate the presence of the mRNA for either BAF155, BAF170, or $\beta$-actin. $\left({ }^{*}\right)$ The muscle actin that was also detected by the $\beta$-actin probe. BAF155 and BAF170 cDNAs match many EST sequences in the dBEST data bank at NCBI. These EST sequences are derived from several different tissues at different developmental stages, suggesting BAF155 and BAF170 were expressed in these tissues. For BAF155, these tissues include: fetal brain (T06718, R95776), infant brain (z43024), testis (T19008, t25695), breast (R50245, t25696, H21971, R55216), placenta (R67673, R24632), melanocyte (N44961, N36960), liver and spleen (R95825, H54140, H53515, R95825). For BAF170, the tissues include: fetal brain (M61970), ovary (T50228), testis (T19008), breast (R73206, H24688, R73142), placenta (R24526, R24632), spleen and liver (T64879, T91030, T50242).

scores: one C. elegans open reading frame CEZK1128-5 (PIR accession no. $z 47357$, BLAST score $10^{-165}$ ), and two Saccharomyces cerevisiae sequences, SCPCPETIT (PIR accession no. s19063, BLAST score $10^{-11}$ ) and YCU2 [SWISS-PROT (SW) accession no. P25632, BLAST score $\left.10^{-10}\right]$. The gene product of SCPCPETIT encodes the SWP73 subunit of the yeast SWI/SNF complex /Cairns et al., this issue). This gene appears to be essential for the function of the SWI/SNF complex, because null mutants have $s w i^{-}$and $s n f^{-}$phenotypes. This gene was referred to as SWP73. The sequence YCU2 is $32 \%$ identical and $54 \%$ similar to SWP73. The alignment of $M B A F 60 a$ with the two yeast genes and the one $C$. elegans gene showed that regions of similarity are present throughout their entire sequences, with many conserved amino acid residues being the same (Fig. 5). BAF60a is therefore a mammalian homolog of yeast SWP73 protein and is likely to play roles similar to those of SWP73 in the yeast complex.

Cloning of a family of human genes that are related to mBAF60a and SWP73

Based on the sequence of $m B A F 60 a$ we isolated a family of human genes very similar to $M B A F 60 a$ by screening cDNA libraries (see Materials and Methods). We referred to its members as human $B A F 60 a, b$, and $c$. The human $B A F 60 a$ gene is likely the gene corresponding to $m B A F 60 a$ in humans, because it has the highest homology to the mouse $m B A F 60 a$ gene at both the DNA $192 \%$ identical) and protein level $(98 \%$ identical and $99 \%$ similar). $h B A F 60 a$ is likely a splicing variant because it lacks a region of the mouse gene mBAF60a /amino acids 384 423; Fig. 5) that is present in all other homologs.

$h B A F 60 b$ and $h B A F 60 c$ are highly similar to $B A F 60 a$ and to each other $\sim \sim 70 \%$ identical and $\sim 80 \%$ similar among all three human genes, Table 2; Fig. 5). hBAF60b encodes a predicted protein of 475 amino acids. Immunoblotting with an antibody against hBAF60b showed that it is not detectable in the complex purified with the BRGl antibody (data not shown). Its immunoreactivity was found to fractionate as a $500-\mathrm{kD}$ complex on a $\mathrm{Su}$ perose 6 sizing column, in contrast to BAF60a, which cofractionates with BRG1 as a complex of $\sim 2 \mathrm{MD}$ (Fig. 6 ; Fig. 9, below). The sequence of $h B A F 60 \mathrm{c}$ predicts a protein of 469 amino acids. BAF60c is highly expressed in muscle cells (Fig. 7, top), in contrast to BAF60b which is expressed in many tissues with the highest level in pancreas (Fig. 7, middle). BAF60a was reported to be ubiquitously expressed (Johnston et al. 1989; Fig. 7, bottom).

All three human genes are roughly equal in similarity to yeast $S W P 73$ and $S W P 73 b$ (Table 2). The alignment of the three human genes with the BAF60/SWP73 genes from other species showed that they have a divergent amino terminus, but most of the carboxy-terminal part of the protein is conserved. The data strongly suggest that BAF60 and SWP73 belong to a large gene family whose products could be involved in nucleosome remodeling. Searching of the PIR data bank or using the University of Wisconsin Genetics Computer Group (UWGCG) program to analyze the BAF60/SWP73 gene family did not reveal any obvious structures or motifs. However, we noticed that the amino-terminal nonconserved region of $B A F 60$ a contains a proline-glycine rich region that is similar to a region in BRG1 and the brm family of proteins.

The hbrm complex has a subunit composition similar to the BRG1 complex

We have shown previously that the two mammalian SWI2 homologs, BRG1 and hbrm, are present in separate complexes (Wang et al. 1996). As demonstrated above, the BRG1 complex purified with BRG1 antibody contains BAF170, BAF155, and BAF60a. All three subunits are homologs of yeast SWI/SNF proteins. Western blots using antibodies against these proteins confirmed their presence in the BRGl complex (Fig. 8a). The complex purified with hbrm antibody contains INI1/hSNF5 as determined by Western blot, and has a pattern of polypeptides on a silver-stained gel similar to that of the BRG1 complex (Wang et al. 1996; see Fig. 8b, cf. lanes 1,2). We immunoblotted the hbrm-associated polypeptides with antibodies against BAF170, BAF155, and BAF60a and found that all three are present in the hbrm complex (Fig. $8 \mathrm{c}$, lane 1). Thus, hbrm and BRG1 complexes have similar subunit compositions, suggesting that they have similar functions in vivo. 
The mammalian SWI/SNF complex contains two SWI3-like subunits

We have shown above that both $B A F 170$ and BAF155 are homologs of the yeast SWI3 gene. Silver stain gels of the complex (Fig. 1b, lanes 1,2; also see Fig. 8b, lanes 1,2) suggest that these two subunits are present in equal molecular ratio in the complex /staining with Coomassie Blue or Ponceau S shows similar results; data not shown). To determine whether BAF170 and BAF155 are in the same complex or separate complexes, we purified BAF170- or BAF155-associated polypeptides using immobilized antibody against BAF 170 or BAF155 and visualized the purified proteins by silver-staining of the SDSPAGE (Fig. 8 b, lanes 3,4 ) and by Western blotting of the eluted polypeptides (Fig. $8 \mathrm{c}$, lanes 2,3 ). The data demonstrate that the mammalian SWI/SNF complexes containing BAF170 also contain BAF155 and that those containing BAF155 also contain BAF170.

The diversity of mammalian SWI/SNF complexes as evidenced by the presence of a distinct $B A F 60 b$ complex

Based on the different tissue distributions of the $\mathrm{mcm}$ bers of the BAF60 gene family, we explored the possibility that they may define biochemically distinct complexes. Using an antibody against the nonconserved amino terminus of BAF $60 \mathrm{~b}$, We affinity-purified the BAF60b-associated polypeptides (see Materials and Methods). The silver-staining pattern of these polypeptides looks remarkably similar to that of the BRG1 complex purified with the BRG1 antibody (Fig. 9a, lanes 2,3), suggesting that they could be similar or identical. Western blotting revealed that the BAF60 complex does not contain any BAF60a immunoreactivity, indicating that BAF $60 \mathrm{~b}$ and BAF60a are indeed subunits of distinct complexes (Fig. 9b). Conversely, the BAF60b complex contains abundant immunoreactivity for BAF170, BAF155, and BAF47, suggesting that these polypeptides are shared between these complexes (Fig. 9c). In addition, the BAF60b complex contains a subunit (referred to as BAF190x; Fig. 9a, lane 3) that has a similar but slightly slower mobility than the BRGl subunit. Western blotting showed that it has very low BRGl immunoreactivity and somewhat higher hbrm reactivity (Fig. 9d). Because several subunits of the mammalian SWI/SNF complex are encoded by gene families, microsequencing will be needed to determine the identities of these BAF60b-associated polypeptides. Preliminary data indicate that in addition to BAF $60 \mathrm{~b}$, at least one other subunit is different from the BRG1 complex (W. Wang and G.R. Crabtree, unpubl.).

We noted that the molecular mass of all subunits of the BAF60b complex is $\sim 1 \mathrm{MD}$, which is bigger than the size determined using a Superose 6 sizing column 1500 $\mathrm{kD}$ ). It is possible that the complex was partially dissociated during the fractionation or that the complex exists in a nonglobular shape. We also noted that the Drosophila NURF complex (Tsukiyama et al. 1995) fractionates at a size similar to the BAF60b complex and contains a subunit of $55 \mathrm{kD}$. We therefore investigated whether BAF60b is a subunit of the human NURF complex. Using an antibody against the human homolog of ISWI, hSNF2L /Okabe et al. 1992; the antibody is a generous gift of Robert Roeder, Rockefeller University, New York), we found that BAF60b and hSNF2L do not have identical chromatographic properties on a Superose 6 sizing column (Fig. 6) or ion-exchange columns (P11 and DE52; data not shown). The complex purified with BAF60 b antibody does not contain immunoreactivity for hSNF2L (Fig. 9d).

\section{Discussion}

\section{Structural and functional similarities between the mammalian and yeast SWI/SNF complexes}

We previously described the complete purification of mammalian SWI/SNF complexes and demonstrated that the complexes are heterogeneous and that they contain homologs of yeast SWI2/SNF2 (BRG1 or hbrm) and SNF5 (INII/hSNF5). The complexes containing BRG1 have nucleosome-disruption activities similar to those of the yeast SWI/SNF complex (Wang et al. 1996). In this report we demonstrate that BAF170, BAF155, and BAF60 are homologs of yeast SWI3 and SWP73 (see also Cairns et al., this issuel. These results and our earlier work establish the close relationship between mammalian and yeast SWI/SNF complexes and strongly support a conserved and universal function for the SWI/SNF complex in all eukaryotes.

\section{Mammalian SWI/SNF complexes contain two different SWI3 homologs}

BAF155 and BAF170 are different homologs of the yeast SWI3 protein. These two subunits are highly similar to each other $(62 \%$ identical and $77 \%$ similar) and both are found in the same complex, because purification of the complex with antibody to one subunit contains the other (Fig. 8). The two proteins also appear to be in equimolar ratio based on visualization by silver staining or Coomassie-blue staining. The presence of a leucine zipper in both BAF155 and BAF170 suggests that these subunits could be contributing to a dimer-like structure by forming heterodimers.

The prediction that the complex has a dimer-like structure can be further supported by molecular weight considerations. The molecular masses of either yeast or mammalian SWI/SNF complex has been determined at 2 MD by Superose 6 sizing columns (Khavari et al. 1993; Peterson et al. 1994). The total molecular weight of all subunits of either the yeast complex (Cairns et al. 1994; Côté et al. 1994) or the mammalian complex is $\sim 1 \mathrm{MD}$, half the size determined by sizing columns. One explanation for this apparent paradox is that some or all subunits of the complex are present in two copies. Our finding that the mammalian SWI/SNF complex contains two different homologs of SWI3 provides the strong evidence for such a model. 
Identification of a myb-like tryptophan repeat domain in the SWI3 family of proteins

We identified a myb-like tryptophan-repeat domain in all SWI3 proteins (Fig. 3cl. This domain was identified originally as tandem repeats in the myb family of proteins (for review, see Luscher and Eisenman 1989) and was recently termed the SANT domain and proposed to be a DNA binding domain (Aasland 1996). The domain is also present in components of two other known chromatin-remodeling complexes, the ADA2/ADA3/GCN5 histone acetyltransferase complex (Horiuchi et al. 1995; Brownell et al. 1996; Candau and Berger 1996) and the NURF complex (Tsukiyama et al. 1995; Tsukiyama and

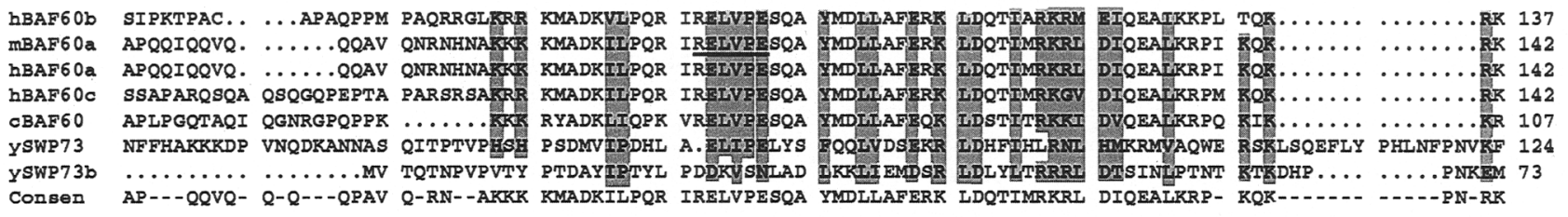

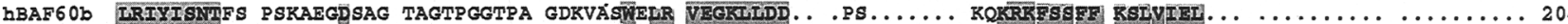

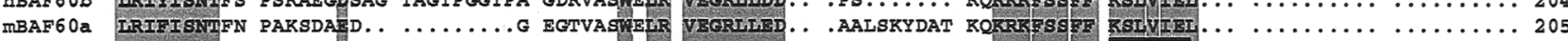

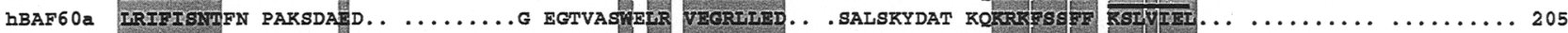

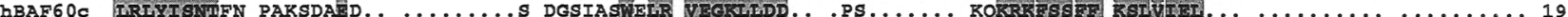
CBAF60

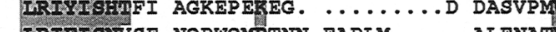
YSWP73b IRTIYYYNITE NQPWQMPTNN EADLM..... ALENATMTMI

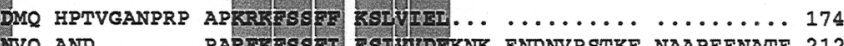
DYVQ AND...... PARHEFSSEI RSI WVDHKNK ENDNVPSTKF NAAPEENATE 212

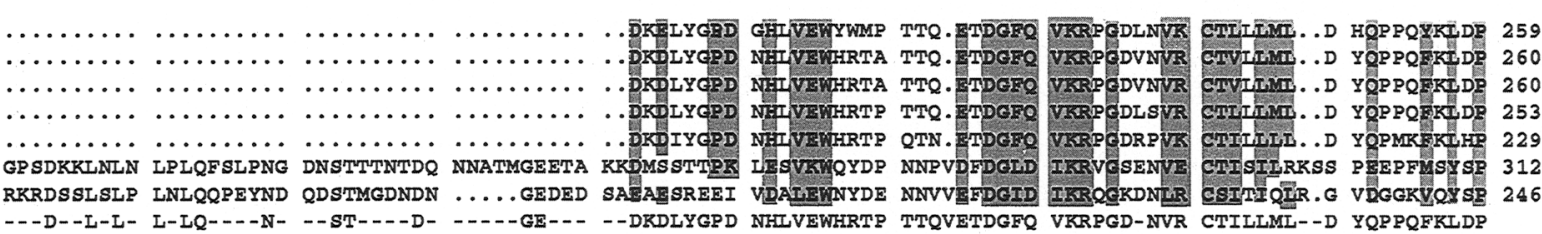

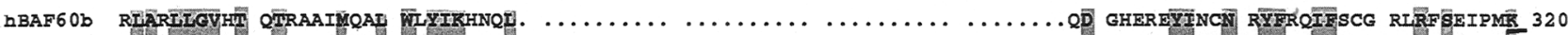

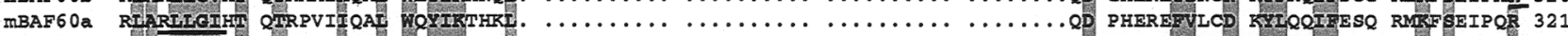

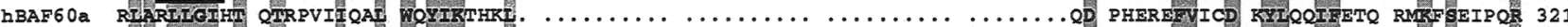

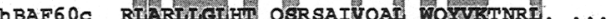

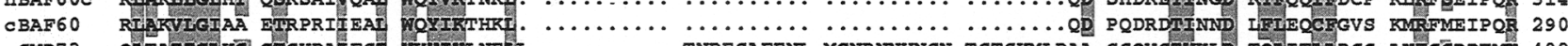

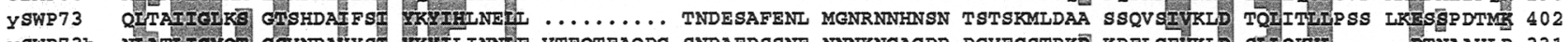
YSWP73b NLATLIGXOM GSVNDAVYSI YKREILINNTF VTEQTEAODG SNDAEDSSNE NNNKNGAGDD DGVEGSTPKD KPELGEVKLD SLIOKVI... ..DTNAAHLP 331

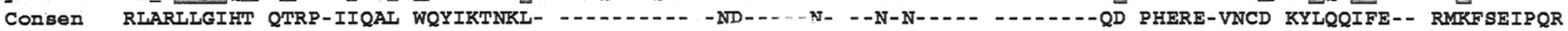

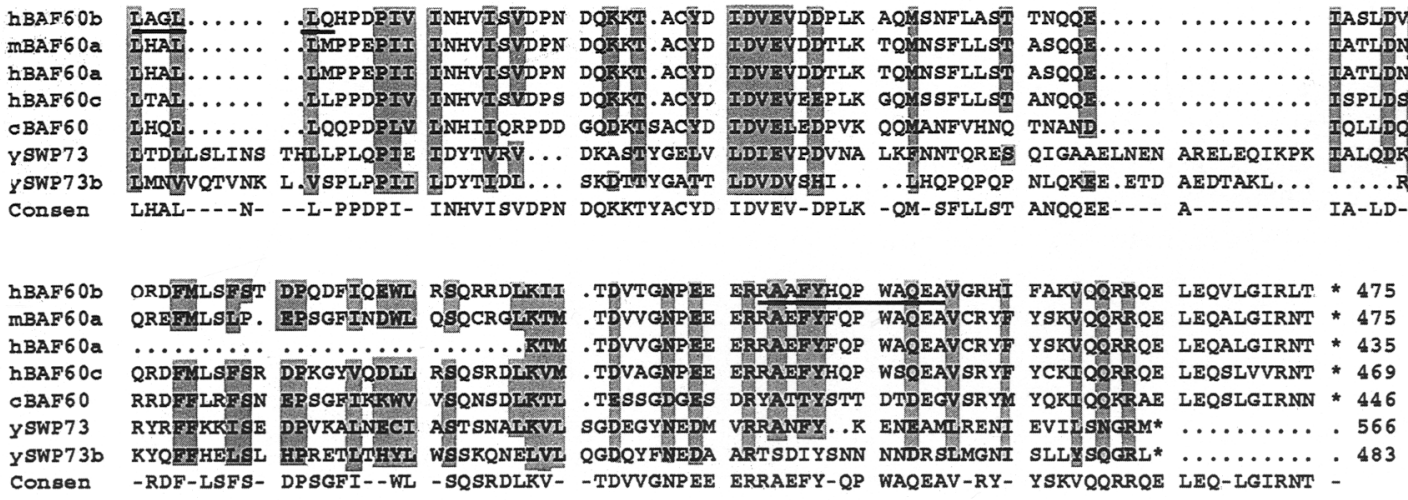

Figure 5. (See facing page for legend.) 


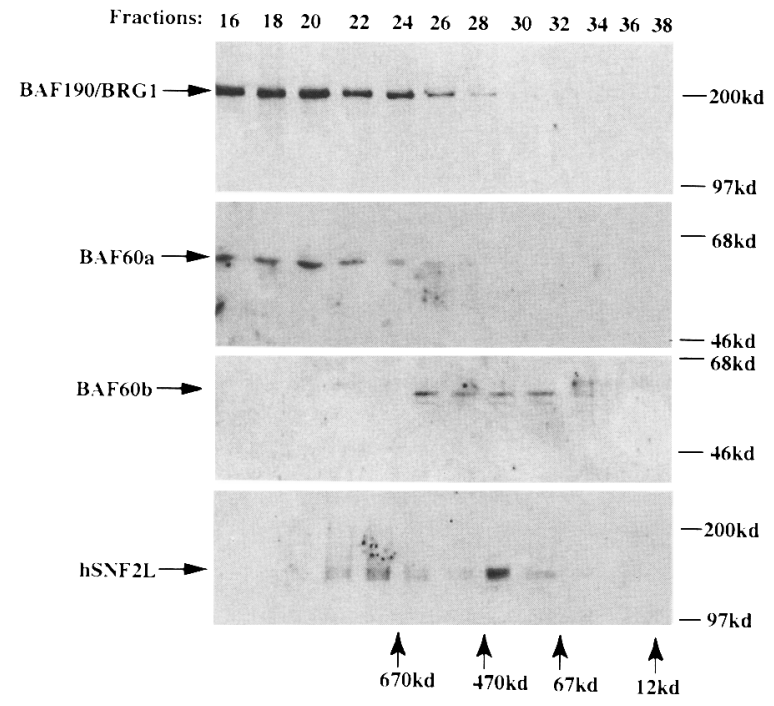

Figure 6. BAF60b fractionates as a separate complex on Superose 6 sizing column. Western blotting analysis after fractionation of nuclear extract of human YT cells (DE52/0.3M fraction) by a Superose 6 sizing column (Pharmacia). Antibodies against BRG1, BAF60a, BAF60b, and hSNF2L were used. The presence of these proteins is indicated by arrows.

Wu 1995), suggesting that it may play a common role in nucleosome-remodeling. However, we have not been able to demonstrate any DNA binding activity using a recombinant protein containing all three conserved regions of BAF170 (data not shown). Careful inspection of amino acid residues that should contact DNA based on the solution structure of c-myb (Ogata et al. 1992) revealed that three out of five residues in the SWI3 SANT domain are hydrophobic where these residues are charged or hydrophilic in c-myb (Fig. 3c). Furthcrmore, the DNA-protein cross-linking studies showed that the subunits in yeast SWI/SNF complex that contact DNA are not SWI3 (Quinn et al. 1996). Thus, the SANT do- main in the SWI3 family of proteins may play a role other than DNA-binding.

BAF60 belongs to a large gene family that includes a novel yeast SWI/SNF subunit, SWP73

We cloned three closely related human BAF60 homologs: $h B A F 60 a, b$ and $c$. These human genes have two yeast homologs (Fig. 5). Cairns et al. (this issue) demonstrate that one of the two yeast homologs encodes a previously uncharacterized SWI/SNF subunit, SWP73. Null mutations in SWP73 have a phenotype that is similar to other SWI/SNF deletions. Furthermore, yeast lacking SWP73 are unable to activate transcription in response to glucocorticoids in yeast strains containing an introduced glucocorticoid receptor gene and a glucocorticoid responsive promoter. Thus, the work in both mammals and yeast indicates that BAF60a/SWP73 is an integral subunit of the SWI/SNF complex.

\section{Mammalian SWI/SNF complexes and pol II holoenzyme}

Recently, the yeast SWI/SNF complex was reported to copurify with SRB proteins and was suggested to be an integral part of the yeast pol II holoenzyme (Wilson et al. 1996). This result is different from previous reports from two other groups using different purification schemes for the SWI/SNF complex (Cairns et al. 1994; Côté et al. 1994). In those purifications, the SWI/SNF complex does not contain other components. To date we have isolated cDNA clones for seven out of nine subunits of mammalian SWI/SNF complexes and none is similar to the subunits of yeast pol II holoenzyme (W. Wang and G.R. Crabtree, unpubl.). The preparation of mammalian pol II holoenzyme has been described recently (Ossipow et al. 1995; Chao et al. 1996). Its pattern on silver-stained gels (Chao et al. 1996) appears to be distinct from that of the purified mammalian SWI/SNF complex. Thus, when us-

Figure 5. Sequence alignment of the BAF60/SWP73 gene family. The sequence alignments of BAF60/SWP73 proteins from mammals, C. elegans, and Saccharomyces cerevisiae. The underlined sequences represent those that are either identical or similar to the peptide sequences obtained from microsequencing. The protcin used for microsequencing is from calf thymus, and is therefore possibly not identical to the reported sequences from mouse or human. One peptide sequence is of high quality: RELVPE (1). The remaining sequences have ambiguity at some positions: KSL(V,g)IE (2); RLLGI $(3)$; KLAGL(L, x) Q $(4)$; KI(H,x)(T,d)IE $(\mathrm{F}, \mathrm{t}) \mathrm{I}(5)$; RAAF(Y,i)/H,e)QP$(\mathrm{W}, \mathrm{I}) \mathrm{A}(\mathrm{Q}, \mathrm{i}) \mathrm{EA}(6)$. The amino acids in parentheses represent differences between the cloned gene (uppercase) and the peptide sequence from microsequencing (lowercase). Peptide 3 is more similar to BAF60a, whereas peptide 4 and 6 are more similar to BAF60b. The remaining peptides do not distinguish between different BAFs. Thus, it appears that BAF60b is present in a large amount in BRG1 complex of calf thymus. The sequence mBAF60a refers to musd $15 \mathrm{kzl}$ (Johnston et al. 1989). The published mouse sequence is 3101 bp, which is similar to the size of the mRNA $(3.2 \mathrm{~kb})$ as determined by Northern blot. It has no starting methionine and also contains a sequencing error that results in its carboxyl terminus being out of frame. Our human BAF60a clone is 2841 bp (mRNA $\sim 4 \mathrm{~kb}$ ) but it contains an extra $150 \mathrm{bp}$ at the 5' end. A stop codon was found in frame to the predicted starting methionine. However, the methionine at codon 14 could be the starting codon because it has a better Kozak sequence (3/5 vs. 0/5). The human BAF60b cDNA clone is $1946 \mathrm{bp}$, smaller than its mRNA $(\sim 3 \mathrm{~kb})$. A stop codon was found upstream in frame to the predicted starting methionine. There is also a methionine in between, but it is present in a GC-rich region and in a context of a poor Kozak sequence. The predicted starting codon make the BAF60b protein similar in size to BA6F60a and BAF60c. The BAF60c cDNA clone is 1724 bp /the mRNA is $\sim 2 \mathrm{~kb}$ ). A stop codon was found upstream in frame with the predicted methionine. cBAF60 refers to an open reading frame identified by the C. elegans genome sequencing project, CEZK1128_5. ySWP73 refers to an open reading frame from Saccharomyces cerevisiae, SCPCPETIT. This sequence was shown to encode the SWP73 subunit of the yeast SWI/SNF complex (Cairns et al., this issue). ySWP73b refers to the yeast sequence YCU2. These sequences were aligned using the Pileup and Pretty programs of UWGCG. 
Table 2. The homology between mammalian BAF60 and yeast SWP73 gene families

\begin{tabular}{lccccc}
\hline Identity/similarity & mBAF60a & hBAF60a & hBAF60b & hBAF60c & cBAF60 \\
\hline mBAF60a & & & & & \\
hBAF60a & $98 / 99 \%$ & & & \\
hBAF60b & $66 / 79 \%$ & $66 / 78 \%$ & & & \\
hBAF60c & $70 / 82 \%$ & $71 / 82 \%$ & $69 / 82 \%$ & & \\
cBAF60 & $55 / 73 \%$ & $56 / 73 \%$ & $52 / 72 \%$ & $55 / 74 \%$ & $25 / 49 \%$ \\
yswp73 & $28 / 51 \%$ & $27 / 51 \%$ & $27 / 50 \%$ & $27 / 50 \%$ & $23 / 47 \%$ \\
yswp73b & $24 / 46 \%$ & $26 / 49 \%$ & $23 / 45 \%$ & $26 / 49 \%$ & $32 / 54 \%$ \\
\hline
\end{tabular}

Each of the mammalian BAF60 homologs or yeast SWP73 homologs were aligned against each other using the Bestfit program of UWGCG. The calculated percentage of identical or similar amino acids are shown as $\%$ identical $\%$ similar. $\mathrm{mBAF} 60 \mathrm{a}$ refers to a known gene, musd $15 \mathrm{kzl}$. cBAF60 refers to a C. elegans open reading frame CEZK1128_5. ySWP73 refers to a yeast open reading frame SCPCPETIT. ySWP73b refers to a yeast open reading frame YCU2 (see text for data-bank access numbers).

ing stringent washing conditions $(0.2 \mathrm{M}$ Guanidine chloride, $0.5 \mathrm{M} \mathrm{NaCl}$ ) for the purification of the of SWI/SNF complexes from mammalian cells, pol II holoenzyme components are not deleted.

\section{Diversity and specialization of mammalian SWI/SNF complexes}

Previously, we have purified two forms of BRG1 complexes and two forms of hbrm complexes from a single mammalian cell line. We showed that BRGl and hbrm are present in separate complexes. The subunit composition of the BRGl complex is also different when purified from several differentiated cell types (Wang et al. 1996). In this work, we find that of the three BAF60 homologs, at least BAF60a and BAF60 b are in separate complexes. Thus, each mammalian SWI/SNF complex may contain a distinct BAF190 (BRGl or hbrm) and a distinct BAF60 (a, b, or $c)$ subunit. In contrast, the two SWI3 homologs, BAFI70 and BAF155, together wth the SNF5 homolog, BAF47, appeared to be the common sub-

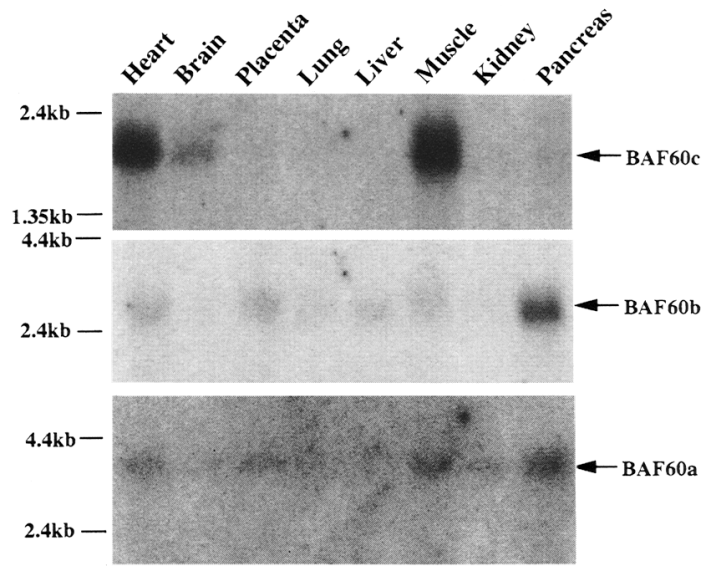

Figure 7. AF60b and BAF60c have different tissue-expression patterns. Northern blot analysis of mRNA from different human tissues as indicated on the top of each lane. This is the same blot used in the experiments of Fig. 4. The arrows indicate the presence of the mRNA for BAF60a, BAF $60 \mathrm{~b}$, and BAF $60 \mathrm{c}$. units present in each complex we purified. They may form a common core with which the different homologs of BAF190 and BAF60 associate in a combinatorial manner. This would give rise to a diverse population of complexes consisting of similar but distinct subunits.

Why are there so many SWI/SNF-like complexes in higher eukaryotes? One possibility is that chromatin remodeling is a highly regulated developmental process in which different SWI/SNF-like complexes are molded to the needs of a differentiated cell, as suggested from the first studies mapping DNase sensitivity of chromatin (Weintraub and Van Lente 1974). The relatively selective expression of BAF60 homologs in different tissues suggests that there may well be tissue-specific chromatin remodeling activity. Further characterization of the chromatin remodeling complexes from different tissues should begin to clarify this issue.

\section{Materials and methods}

\section{Purification of the mammalian SWI/SNF complexes}

The purification procedure of different SWI/SNF complexes has been described in detail in Wang et al. (1996). Briefly, the nuclear extracts were fractionated over P-11 (Whatman) and DE52 (Whatman) ion-exchange columns (see Fig. la) and a S300 (Pharmacia) sizing column. The presence of the SWI/SNF complex was followed by Western blotting with antibodies against BRGl, hbrm, hSNF5, and BAF60b (Wang et al. 1996). The fractionated extract was then loaded onto antibody columns that were made by cross-linking different antibodies to ProteinSepharose beads (Pharmacia) according to the protocols in Harlow and Lane (1988). The columns were thoroughly washed using $0.5 \mathrm{M}$ buffer $\mathrm{D}[0.5 \mathrm{M} \mathrm{KCl}, 20 \mathrm{~mm}$ HEPES (pH 7.9), $0.25 \mathrm{~mm}$ EDTA, $10 \%$ glycerol, $0.1 \%$ Tween 20 , and $0.2 \mathrm{M}$ guanidine hydrochloride. The SWI/SNF complex was then eluted under mild acidic conditions $(0.2 \mathrm{M}$ glycine at $\mathrm{pH} 2.5)$ directly into neutralizing buffer, $1 \mathrm{M}$ TrisHCl $(\mathrm{pH} 8.0)$. The purification of the BAF $60 \mathrm{~b}$ complex is similar to the purification of the BRGl complex, except that the column was washed at $0.1 \mathrm{M}$ guanidine hydrochloride.

\section{Microsequencing of the subunits of the BRG1 complex}

The peak fractions containing BRGl complex A from BRG1 antibody columns were pooled and the proteins concentrated by 


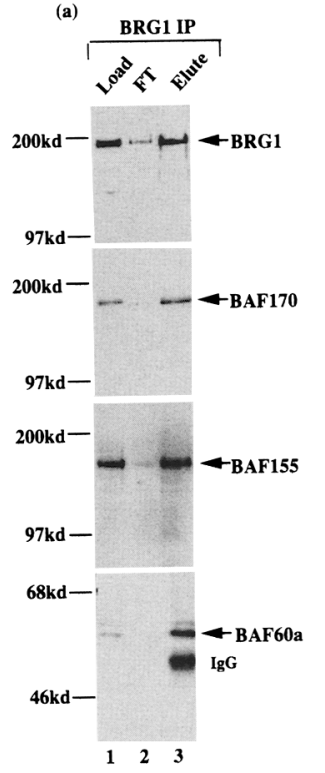

(b)

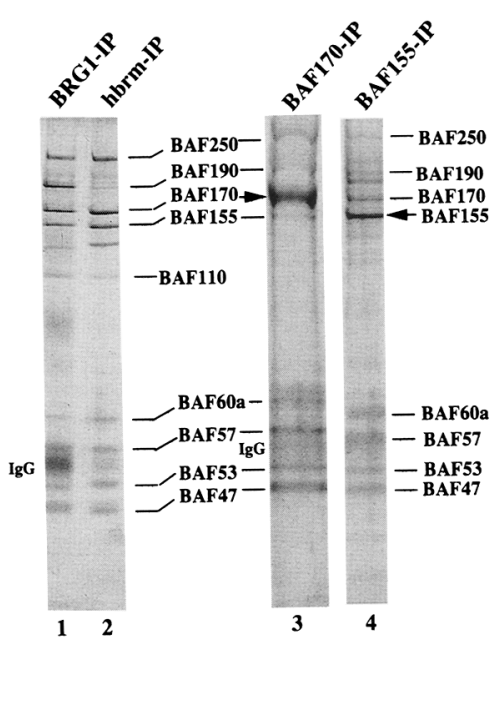

(c)

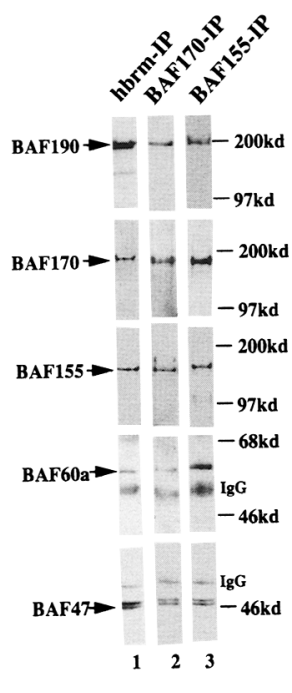

Figure 8. Mammalian SWI/SNF complex contains two SWI3 homologs and an SWP73 homolog. (a) Western blot analysis of load, flowthrough (FT), and eluted fractions of the BRG1 antibody column. Each fraction is indicated on the top of each lane. The arrows indicate BRG1, BAF170, BAF155, and BAF60a. (b) The silver-staining gel of complexes purified with different antibody columns as marked on top of each lane. The lines indicate the bands corresponding to each BAF. The arrows indicate BAF170 and BAF155, which are present in above-stoichiometric amounts in complexes purified by their own antibodies. This is in contrast to complexes purified with BRG1, INI//hSNF5, or hbrm antibodies in which the amount of BAF170 and BAF155 are stoichiometric (see Fig. 1b, lanes 1,2; Fig. 8b, lanes 1,2). The data suggest that some BAF170 and BAF155 is not associated with BRGl or hbrm complexes and could be immunopurified preferentially

by their antibodies. Another possibility is that complexes containing homodimers of either BAF170 or BAF155 are present in cells and are purified preferentially by the corresponding antibodies. Our previous findings that SWI/SNF complexes purified from some cell lines contain substochiometric amounts of BAF170 support this view (Wang et al. 1996). A third possibility is that some BAF170 and 155 are associated loosely with mammalian SWI/SNF complexes, and they dissociate during purification. $(c)$ Western blot analysis of complexes purified with different antibody columns as shown on the top of cach lane. The arrows indicate the immunoreactivity of each BAF. We have frequently observed that the BAF47/hSNF5 antibody recognizes two bands. We suspect that the protein might be phosphorylated.

TCA precipitation. The proteins were separated by preparative SDS-PAGE $(7.5 \%)$. The gel was then cut into two halves. The gel containing lower-molecular-weight proteins /smaller than the 66-kD marker) was transferred to PVDF membrane and visualized by Ponceau S-staining. The band containing BAF 60 was excised and digested with trypsin (Boehringer-Mannheim, sequencing grade) overnight. The other half of the gel containing higher-molecular-weight proteins (larger than the $97 \mathrm{kD}$ marker) was negatively stained with $\mathrm{ZnCl}_{2}$ and developed in imidazole (Zhou and Admon 1995). The bands containing BAF170 and BAF155 were excised and digested with Lys-C endoproteinase (WAKO). The peptides eluted from the PVDF membrane or the gel slice were separated by reverse-phase HPLC and sequenced by automatic amino acid sequencer.

\section{Cloning of the BAF155 subunit.}

BA6F155 was purified using human KB cells as the source. The sequence of four peptides obtained after Lys-C digestion did not match any known genes in the NR databank at NCBI searched with the BLAST program. Luckily, one long peptide sequence (corresponding to amino acids 924-944, Fig. 2) was found to match a human expressed sequence tag (EST) sequence from The Institute of Genomic Research (TIGR) databank (ID no. EST18238, corresponding to amino acids $880-949$ of the cloned BAF155|. BLAST search with this EST sequence revealed that it is similar to the yeast SWI3 gene. Two oligonucleotides (nucleotides 3-21 and 214-196/ were used as primers to amplify the EST sequence by PCR. Human cDNA from Jurkat T-cells was used as the template for the PCR reaction.

The PCR product obtained was then used as a template to make ${ }^{32} \mathrm{P}$-labeled probes to screen cDNA libraries. The hybridized filters were washed twice under low stringency conditions
(2× SSC and $0.1 \%$ SDS, room temperature) and twice under high-stringency conditions, $0.1 \times \mathrm{SSC}$ and $0.1 \% \mathrm{SDS}$ at $65^{\circ} \mathrm{C}$. Over 100 positive clones have been identified. They were analyzed by restriction digestion and PCR mapping and classified into different groups. The representative clones from each group were sequenced, and three overlapping clones were found to encode a single open reading frame containing all peptide sequences from microsequencing.

\section{Cloning of BAF170}

BAF170 was purified from human $\mathrm{KB}$ cells, and three high-quality peptide sequences were obtained after Lys-C endoproteinase digestion (Fig. 2a). These sequences do not match any known genes or EST sequences in the data bank. Two degenerate oligos were synthesized based on the longest peptide sequence (amino acids $728-748$ of the cloned BAF170, Fig. 2a). The oligo sequences are: $5^{\prime}$-AA/G/A)GCIGA/C/T)CCIGCITT/C/T)GG-3' and $5^{\prime}$-GTIGTICCIGCIATICC-3'. They were used for internal PCR reactions using human $\mathrm{cDNA}$ from Jurkat $\mathrm{T}$-cells as the template. After amplification ( 2 rounds, 25 cycles each round), the PCR products were separated by $8 \%$ nondenaturing PAGE. The DNA fragment with the expected size of $60 \mathrm{bp}$ was excised and cloned into a PGEM-T vector (Promega). Four random clones containing the insert were sequenced and found to contain the predicted sequence based on the four middle amino acids. A 23-nucleotide oligo was then synthesized based on the amplified sequence: 5 '-GGTCTGGAAAGCAGTGGCATCGC$3^{\prime}$. It was ${ }^{32} \mathrm{P}$-labeled by $\mathrm{T} 4$ kinase and used as a probe to screen cDNA libraries under low-stringency washing conditions $(2 \times$ SSC, $0.1 \%$ SDS, $42^{\circ} \mathrm{C}, 2 \times 15 \mathrm{~min}$; room temperature $2 \times 15$ min). Over 20 clones were obtained. One group of clones was found to contain the predicted sequence based on the peptide 
Figure 9. The diversity of mammalian SWI/SNF complexes as evidenced by the presence of a distinct BAF $60 \mathrm{~b}$ complex. $(a)$ Silver-staining gel of the affinity-purified complex using either BRG1 antibody (lane 2) or BAF $60 \mathrm{~b}$ antibody (lane 3) from human YT cells. The polypeptides that have similar mobilities in both complexes are marked. Since no microsequencing has been done for the BAF60b-associated polypeptides, their identities cannot be conclusively determined by simple use of Western blotting data. They were referred to as BAFx. However, the presence of strong immunoreactivity of BAF155, BAF170 and BAF47/hSNF5 suggest that these polypeptides are also subunits of the BAF $60 \mathrm{~b}$ complex. The BAF110 band is missing in this preparation of the BRGl complex. We find that BAF110 can sometimes be washed away when using a BRGl antibody column, but it is always present when using BAF47/hSNF5 antibody column. $(b-d)$ Western blot analysis of the load, flowthrough (FT), and elute fractions of the BAF $60 \mathrm{~b}$ affinity column, respectively, as indicated on the top of each lane. The presence of the immunoreactivity was marked with an arrow. (*) The cross-linked IgG coming off the affinity column that was recognized by the secondary antibody. We noticed that the immunoreactivities of BAF60a, BAF155, BAF170, and BAF47/hSNF5 are all detectable in the flowthrough fraction of the BAF60b antibody column, whereas the reactivities for BRGl and hbrm were not detected. The data imply that these subunits could be components of complexes other than BRGl and hbrm. We found that the BRGl and hbrm complexes are very "sticky" and can be precipitated nonspecifically by several unrelated antibodies. The complexes could then be washed off under high-stringency washing conditions. This could be the reason why BRGl and hbrm complexes were depleted in the BAF60b antibody flowthrough fractions and were also present at low levels in the elute fractions.

sequence. The longest clone was sequenced and found to contain a cDNA of $4022 \mathrm{bp}$. A single open reading frame of 1213 amino acids was identified that contained all three peptide sequences obtained by microsequencing.

\section{Cloning the BAF60 family of proteins}

The BAF 60 subunit was purified from calf thymus. The peptides obtained were either identical or similar to a published sequence in the data bank, musd $15 \mathrm{kzl}$ (Fig. 4). To clone the human homologs of BAF 60 , the mouse sequence was used to search the human EST sequence data bank at TIGR and dBEST data bank at the National Center for Biotechnology Information (NCBI). Five EST sequences were found with high scores.

\begin{tabular}{|c|c|c|c|}
\hline Human EST & Data bank & Probability & Gene \\
\hline$\overline{\text { EST64722 }}$ & $\overline{\mathrm{TIGR}}$ & $10^{-70}$ & $\overline{B A F 6} 0 a$ \\
\hline THC48547 & TIGR & $10^{-87}$ & $B A F 60 b$ \\
\hline F05831 & EMBL & $10^{-50}$ & $B A F 60 \mathrm{c}$ \\
\hline THC 44070 & TIGR & $10^{-124}$ & $B A F 60 C$ \\
\hline EST04790/T06901 & TIGR/dbest & $10^{-18}$ & Unknown \\
\hline
\end{tabular}

Oligonucleotides were designed based on the first three EST sequences for PCR amplification of each sequence. The oligos for each sequence are: EST64722 (nucleotides 2-20 and 224 207), THC48547 (nucleotides 7-24 and 316-299), and F05831 (nucleotides 28-46 and 234-217). The cDNA from Jurkat cells was used as a template for PCR reaction. The amplified PCR products were used as probes to obtain CDNAs as described above (see cloning of BAF155).

\section{Preparation of antibodies and immunoaffinity purifications}

Rabbit polyclonal antibodies against BRG1, hbrm and hSNF5/ INI1/BAF47 have been described previously (Wang et al. 1996).
The antibodies used in this work are all rabbit polyclonal antibodies. The immunogens are fusion proteins containing either glutathione $S$-transferase (GST) or the maltose binding protein (MBP) fused to a region of the cloned subunit. The region used for immunization for BAF155 is amino acids 872-949 (fused to $\mathrm{MBP}$ ); for BAF170, amino acids $744-857$ (fused to $\mathrm{MBP}$ ); for BAF60a, two antibodies were made against two different regions: amino acids 80-276 (fused to MBP) and 280-475 (fused to GST); for BAF60b, amino acids 26-93 (fused to MBP). The antibodies were all affinity-purified using the corresponding immunogen as affinity ligands (Harlow and Lane 1988). All except BAF60a antibodies work on immunoprecipitation. They were cross-linked to Protein-A Sepharose (Pharmacia) with DMP (Harlow and Lane 1988) and were used for affinity purification of complexes (Wang et al. 1996).

\section{Northern blot}

The human multitissue blot was from Clontech and was probed with a 4.4-kb fragment of cDNA for $h B A F 155$ and a $2.6-\mathrm{kb}$ fragment of $h B A F 170 \mathrm{cDNA}$. The full-length cDNAs for $h B A F 60 a$, $b$ and $c$ were used as probes. The $\beta$-actin probe was provided by the manufacturer. The probes were labeled by ${ }^{32} \mathrm{P}$-dCTP using Klenow and random hexamers as primers $(1-2$ million $\mathrm{cpm} / \mathrm{ml})$. After hybridization, the blot was washed at high-stringency conditions $\left(0.1 \times \mathrm{SSC}, 0.1 \% \mathrm{SDS}, 2 \times 10 \mathrm{~min}\right.$ at $\left.55^{\circ} \mathrm{C}\right)$ and $\mathrm{ex}-$ posed to Kodak X-ray films for 1-3 days. The same blot was washed and reprobed multiple times using different probes as described above.

\section{Acknowledgments}

We thank R. Tjian for his strong support throughout this project. W.W. has been supported by a Fellowship from the Cancer Research Fund of the Damon Runyon-Walter Winchell Foun- 
dation, DRG-1182. This work has been supported by the Howard Hughes Medical Institute and a grant from the National Institutes of Health to G.R.C. We are very grateful to Dr. Robert Roeder for the hSNF2L antibody. We appreciate highly those scientists who have contributed to the EST data bases at NCBI and TIGR. We thank S. Ho, H. Bayle, and L. Timmerman for critical reading of the manuscript. We thank J. Obcrlindacher for help in preparation of this manuscript. The genes cloned in this work have been submitted to GenBank under accession numbers U66615 (BAF155); U66616 (BAF170); U66617 (human BAF60a); U66618 (BAF60b); U66619 (BAF60c), and U66620 (mouse BAF60a).

The publication costs of this article were defrayed in part by payment of page charges. This article must therefore be hereby marked "advertisement" in accordance with 18 USC section 1734 solely to indicate this fact.

\section{References}

Aasland, R. 1996. The SANT domain: a putative DNA-binding domain in the SWI-SNF and ADA complexes, the transcriptional co-repressor NCoR and TFIIIB. TIBS 21: 87-88.

Breeden, L. and K. Nasmyth. 1987. Cell cycle control of the yeast HO gene: cis- and trans-acting regulators. Cell 48: 389-397.

Brizuela, B.J., L. Elfring, J. Ballard, J.W. Tamkun, and J.A. Kennison. 1994. Genetic analysis of the brahma gene of Drosophila melanogaster and polytene chromosome subdivisions 72AB. Genetics 137: 803-813.

Brownell, J.E., J. Zhou, T. Ranalli, R. Kobayashi, D.G. Edmondson, S.Y. Roth, and C.D. Allis. 1996. Tetrahymena histone acetyl transferase A: A homolog to ycast GCN5p linking histone acetylation to gene activation. Cell 84: 843-851.

Cairns, B.R, Y.-J. Kim, M.H. Sayes, B.C. Laurent, and R.D. Kornberg. 1994. A multisubunit complex containing the SWI1/ADR6, SWI2/SNF2, SWI3, SNF5, and SNF6 gene products isolated from yeast. Proc. Nat1. Acad. Sci. 91: 19501954.

Cairns, B.R, N.L. Henry, and R.D. Kornberg. 1996a. TFG3/ TF30/ANC1, a component of the yeast SWI/SNF complex that is similar to the leukemogenic proteins ENL and AF-9. Mol Cell. Biol. 16: 3308-3316.

Cairns, B.R., R.S. Levinson, K.R. Yamamoto, and R.D. Kornberg. 1996b. Essential role of Swp73p in function of the yeast Swi/Snf complex. Genes \& Dev. (this issue).

Candau, R. and S.L. Berger. 1996. Structural analysis of yeast putative adaptors. J. Biol. Chem. 271: 5237-5245.

Carlson, M. and B.C. Laurent. 1994. The SNF/SWI family of global transcriptional activators. Curr. Opin. Cell Biol. 6: 396-402.

Chao, D.M., E.L. Gadbois, P.J. Murray, S.F. Anderson, M.S. Sonu, J.D. Parvin, and R.A. Young. 1996. A mammalian SRB protein associated with an RNA polymerase II holoenzyme. Nature 380: 382-385.

Chiba, H., M. Muramatsu, A. Nomoto, and H. Kato. 1994. Two human homologues of Saccharomyces cerevisiae SWI2/ SNF2 and Drosophila brahma are transcriptional coactivators cooperating with the estrogen receptor and the retinoic acid receptor. Nucleic Acids Res. 22: 1815-1820.

Côté, J., J. Quinn, J.L. Workman, and C.L. Peterson. 1994. Stimulation of GAL4 derivative binding to nucleosomal DNA by the yeast SWI/SNF complex. Science 265: 53-60.

Courey, A.J., D.A. Holtzman, S.P. Jackson, and R. Tjian. 1989. Synergystic activation by the glutamine-rich domains of human transcription factor Spl. Cell 59: 827-836.
Dingwall, A.K., S.J. Beek, C.M. McCallum, J.W. Tamkun, G.V. Kalpana, S.P. Goff, and M.P. Scott. 1995. The Drosophila snrl and brm proteins are related to yeast SWI/SNF proteins and are components of a large protein complex. Mol. Biol. Cell 6: 777-791.

Harlow, E. and D. Lane. 1988. Antibodies: A laboratory manual. Cold Spring Harbor Laboratory Press, Cold Spring Harbor, NY.

Hirschhorn, J.N., S.A. Brown, C.D. Clark, and F. Winston. 1992. Evidence that SNF2/SWI2 and SNF5 activate transcription in yeast by altering chromatin structure. Genes \& Dev. 6: $2288-2298$.

Hirschhorn, J.N., A.L. Bortvin, S.L. Ricupero-Hovasse, and F. Winston. 1995. A new class of histone H2A mutations in Saccharomyces cerevisiae causes specific transcriptional defects in vivo. Mol. Cell. Biol. 5: 1999-2009.

Horiuchi, I., N. Silverman, G.A. Marcus, and L. Guarente. 1995. $\mathrm{ADA} 3$, a putative transcriptional adaptor, consists of two scparable domains and interacts with ADA2 and GCN5 in a trimeric complex. Mol. Cell. Biol. 15: 1203-1209.

Horlein, A.J., A.M. Naar, T. Heinzel, J. Torchia, B. Gloss, R. Kurokawa, A. Ryan, Y. Kamei, M. Sorderstrom, C.K. Glass, and M.G. Rosenfeld. 1995. Ligand-independent repression by the thyroid hormone receptor mediated by a nuclear receptor co-repressor. Nature 377: 397-404.

Imbalzano, A.N., H. Kwon, M.R. Green, and R.E. Kingston. 1994. Facilitatcd binding of TATA-binding protein to nucleosomal DNA. Nature 370: 481-485.

Johnson, P.F. and S.L. McKnight. 1989. Eukaryotic transcriptional regulatory proteins. Ann. Rev. Biochem. 58: 799-839.

Johnston, L.A., M.A. Kotarski, D.J. Jerry, and L.P. Kozak. 1989. An ubiquitously expressed gene 3.5 kilobases upstream of the glycerol-3-phosphate dehydrogenase gene in mice. Mol. Cell. Biol. 9: 935-945.

Kalpana, G.V., S. Marmon, W. Wang, and G.R. Crabtree. 1994. Binding and stimulation of HIV-1 integrase by a human homolog of yeast transcription factor SNF5. Science 266: 2002-2006.

Kassavetis, G.A., S.T. Nguyen, R. Kobayashi, A. Kumar, E.P. Geiduschek, and M. Pisano. 1995. Cloning, expression, and function of TFC5, the gene encoding the $\mathrm{B}^{\prime \prime}$ component of the Saccharomyces cerevisiae RNA polymerase III transcription factor TFIIIB. Proc. Natl. Acad. Sci. 92: 9786-9790.

Kennison, J.A. and J.W. Tamkun. 1988. Dosage-dependent modifiers of polycomb and antennapedia mutations in Drosophila. Proc. Natl. Acad. Sci. 85: 8136-8140.

Khavari, P.A., C.L. Peterson, J.W. Tamkun, D.B. Mendel, and G.R. Crabtree. 1993. BRG1 contains a conserved domain of the SWI2/SNF2 family necessary for normal mitotic growth and transcription. Nature 366: 170-174.

Kruger, W., C.L. Peterson, A. Sil, C. Coburn, G. Arents, E.N. Moudrianakis, and I. Herskowitz. 1995. Amino acid substitutions in the structured domains of histones $\mathrm{H} 3$ and $\mathrm{H} 4$ partially relieve the requirement of the yeast SWI/SNF complex for transcription. Genes \& Dev. 9: 2770-2779.

Kwon, H., A.N. Imbalzano, P.A. Khavari, R.E. Kingston, and M.R. Green. 1994. Nucleosome disruption and enhancement of activator binding by a human SW1/SNF complex. Nature 370: 477-481.

Laurent, B.C. and M. Carlson. 1992. Yeast SNF2/SWI2, SNF5, and SNF6 proteins function coordinately with the gene-specific transcriptional activators GAL4 and Bicoid. Genes \& Dev. 6: $1707-1715$.

Luscher, B. and R.N. Eisenman. 1990. New light on myc myb. Part II. myb. Genes \& Dev. 4: 2235-2241.

McGhee, J.D., W.I. Wood, M. Dolan, I.D. Engel, and G. Felsen- 
feld. 1981. A 200 base pair region at the $5^{\prime}$ end of the chicken adult beta-globin gene is accessible to nuclease digestion. Cell 27: 45-55.

Mermod, N., E.A. O'Neill, T.J. Kelly, and R. Tjian. 1989. The proline-rich transcriptional activator of CTF/NF-1 is distinct from the replication and DNA binding domain. Cell 58: $741-753$.

Moehrle, A. and R. Paro. 1994. Spreading the silence: Epigenetic transcriptional regulation during Drosophila development. Dev. Genetics 15: 478-484.

Muchardt, C. and M. Yaniv. 1993. A human homologue of Saccharomyces cerevisiae SNF2/SWI2 and Drosophila brm genes potentiates transcriptional activation by the glucocorticoid receptor. $E M B O$ J. 12: 4279-4290.

Muchardt, C., C. Sardet, B. Bourachot, C. Onufryk, and M. Yaniv. 1995. A human protein with homology to Saccharomyces cerevisiae SNF5 interacts with the potential helicase hbrm. Nucleic Acids Res. 23: 1127-1132.

Neigeborn, L. and M. Carlson. 1984. Genes affecting the regulation of SUC2 gene expression by glucose repression in Saccharomyces cerevisiae. Genetics 108: 845-858.

Ogata, K., H. Hojo, S. Aimoto, T. Nakai, H. Nakamura, A. Sarai, S. Ishii, and Y. Nishimura. 1992. Solution structure of a DNA-binding unit of Myb: A helix-turn-helix-related motif with conserved tryptophans forming a hydrophobic core. Proc. Natl. Acad. Sci. 89: 6428-6432.

Okabe, I., L.C. Bailey, O. Attree, S. Srinivasan, J.M. Perkel, B.C. Laurent, M. Carlson, D.L. Nelson, and R.L. Nussbaum. 1992. Cloning of human and bovine homologs of SNF2/ SWI2: a global activator of transcription in yeast $\mathrm{S}$. cerevisiae. Nucleic Acids Res. 20: 4649-4655.

Ossipow, V., J.-P. Tassan, E.A. Nigg, and U. Schibler. 1995. A mammalian RNA polymerase II holoenzyme containing all components required for promoter-specific transcription initiation. Cell 83: 137-146.

Peterson, C.L. and I. Herskowitz. 1992. Characterization of the yeast SWI1, SWI2, and SWI3 genes, which encode a global activator of transcription. Cell 68: 573-583.

Peterson, C.L., A. Dingwall, and M.P. Scott. 1994. Five SWI/ SNF gene products are components of a large multisubunit complex required for transcriptional enhancement. Proc. Natl. Acad. Sci. 91: 2905-2908.

Peterson, C.L. and J.W. Tamkun. 1995. The SWI-SNF complex: A chromatin remodeling machine. TIBS 20: 143-146.

Prelich, G. and F. Winston. 1993. Mutations that suppress the deletion of an upstream activating sequence in yeast: Involvement of a protein kinase and histone $\mathrm{H} 3$ in repressing transcription in vivo. Genetics 135: 665-676.

Quinn, I., A.M. Fryberg, R.W. Ganster, M.C. Schmidt, and C.L. Peterson. 1996. DNA-binding properties of the yeast SWI/ SNF complex. Nature 379: 844-847.

Siebenlist, U., D.B. Durand, P. Bressler, N.J. Holbrook, C.A. Norris, M. Kamoun, J.A. Kant, and G.R. Crabtree. 1986. Promoter region of interleukin-2 gene undergoes chromatin structure changes and confers inducibility on chloramphenicol acetyltransferase gene during activation of T cells. Mol. Cell. Biol. 6: 3042-3049.

Stern, M., R. Jensen, and I. Herskowitz. 1984. Five SWI genes are required for expression of the HO gene in yeast. J. Mol. Biol. 178: 853-868.

Tamkun, J.W., R. Deuring, M.P. Scott, M. Kissinger, A.M. Pattatucci, T.C. Kaufman, and J.A. Kennison. 1992. brahma: a regulator of Drosophila homeotic genes structurally related to the yeast transcriptional activator SNF2/SWI2. Cell 68: $561-572$.

Travers, A.A. 1992. The reprogramming of transcriptional com- petence. Cell 69: 573-575.

Treich, I., B.R. Cairn, T. Santos, E. Brewster, and M. Carlson. 1995. SNF11, a new component of the yeast SNF-SWI complex that interacts with conserved region of SNF2. Mol. Cell. Biol. 15: $4240-4248$.

Tsukiyama, T., C. Daniel, J. Tamkun, and C. Wu. 1995. ISWI, a member of the SWI2/SNF2 ATPase family, encodes the 140 kd subunit of the nucleosome remodeling factor. Cell 83: 1021-1026.

Tsukiyama, T. and C. Wu. 1995. Purification and properties of an ATP-dependent nucleosome remodeling factor, Cell 83: $1011-1020$.

Wang, W., J. Côté, Y. Xue, S. Zhou, P.A. Khavara, S.R. Biggar, C. Muchardt, G.V. Kalpana, S.P. Goff, M. Yaniv, J.L. Workman, and G.R. Crabtree. 1996. Purification and biochemical heterogeneity of the mammalian SWI/SNF complex. EMBO $)$ (in press).

Weintraub, H. and F. Van Lente. 1974. Dissection of chromosome structure with trypsin and nucleases. Proc. Natl. Acad. Sci. 71: 4249-4253.

Weintraub, H. and M. Groudine. 1976. Chromosomal subunits in active genes have an altered conformation. Science 193: $848-856$.

Wilson, C.I., D.M. Chao, A.N. Imbalzano, G.R. Schnitzler, R.E. Kingston, and R.A. Young. 1996. RNA polymerase II holoenzyme contains SWI/SNF regulators involved in chromatin remodeling. Cell 84: 235-244.

Winston, F. and M. Carlson. 1992. Yeast SNF/SWI transcriptional activators and the SPT/SIN chromatin connection. TIG 8: 387-391.

Wolffe, A.P. 1994. Transcription: In tune with the histones. Cell 77: 13-16.

Wu, C. and W. Gilbert. 1981. Tissue-specific exposure of chromatin structure at the $5^{\prime}$ terminus of the rat preproinsulin II gene. Proc. Natl. Acad. Sci. 78: 1577-1580.

Yoshinaga, S.K., C.L. Peterson, I. Herskowitz, and K.R. Yamamoto. 1992. Roles of SWI1, SWI2, and SWI3 proteins for transcriptional enhancement by steroid receptors. Science 258: 1598-1604.

Zhou, S. and A. Admon. 1995. Enzymatic digestion of proteins in zinc chloride and Ponceau S stained gels. In Techniques in protein chemistry VI (ed. J.W. Crabb), pp. 161-167. Academic Press, San Diego, CA. 


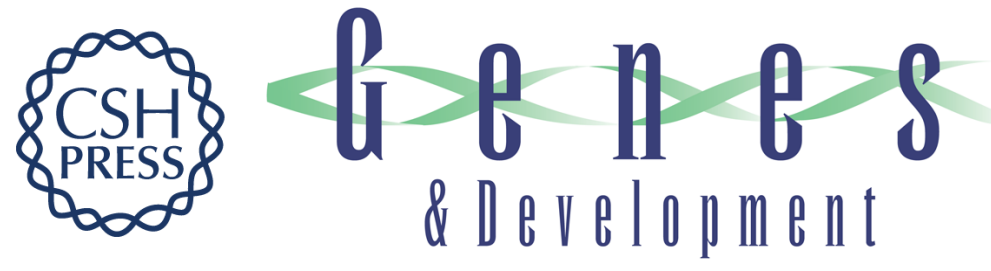

\section{Diversity and specialization of mammalian SWI/SNF complexes.}

W Wang, Y Xue, S Zhou, et al.

Genes Dev. 1996, 10:

Access the most recent version at doi:10.1101/gad.10.17.2117

References This article cites 56 articles, 25 of which can be accessed free at: http://genesdev.cshlp.org/content/10/17/2117.full.html\#ref-list-1

License

Email Alerting

Receive free email alerts when new articles cite this article - sign up in the box at the top Service right corner of the article or click here.

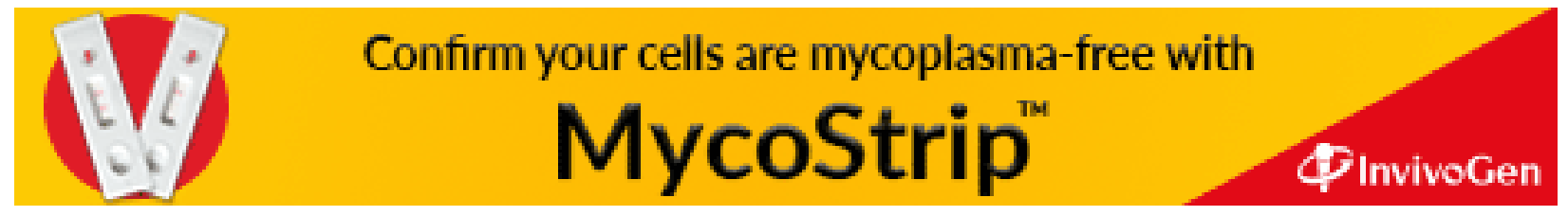

